\title{
Design Ethics Education in Taiwan: A Study of Syllabi of Ethics-Related Courses
}

\author{
Manlai You and Yingying Lee \\ Greduate School of Design, National Yunlin University of Science and Technology, \\ 123 University Road, Section 3, Douliu, Yunlin 64002, Taiwan \\ \{youm, Ug9730816\} @yuntech. edu.tw
}

\begin{abstract}
This paper aims to identify the scope and content of ethics components in the curricula of regular 4-year undergraduate design programs in Taiwan by investigating the syllabi of ethics-related courses. Of the 148 universities and colleges in Taiwan, there were 117 regular 4-year undergraduate design programs in 61 institutions during academic years 2008 and 2009. A list of ethics-related courses was obtained from two web-based curricular databases of the Ministry of Education (MOE), which consists of 38 unique syllabi from 29 design programs in 17 institutions. Each of them was then processed by qualitative method taking advantage of the standard format of syllabus in Taiwan. The contents classified into four generic parts: 1) course objectives, 2) course contents, 3) teaching methods, and 4) assessment methods. Of the 38 syllabi, five topics, Design, Profession, Law, Society, and Life, were identified from the parts of course objectives and contents. In the parts of teaching methods and assessment methods, seven and nine methods were identified respectively. The results reveal what and how we treat ethics as a topic in design education in Taiwan. The paper concludes with some suggestions on further research of design ethics education.
\end{abstract}

Keywords: Design Ethics, Design Education, Syllabus, Ethics-Related Courses.

\section{Introduction}

Design education has a history of about 50 years in Taiwan and the design profession has become popular and well recognized in society since the 1980s due to Taiwan government's significant effort and enterprises' increasing emphases on design [1-2]. While we focus on the outer dimension of design education, i.e., the innovative and applicable techniques, the inner dimension of how we cultivate future designers is relatively rarely discussed. Since Victor Papanek raised the ethical issues in design practices and education 40 years ago [3], gradually a number of scholars have continuously kept on discussions and studies in the related issues. From critiques on the ideology of design to social phenomena [4], to the explorations of design theories and practices for ethics, social responsibility, and global justice issues [5-9]. All of 
them recognize the vital importance of ethics as a topic in design but researches describing current practices in design ethics education have scarcely been formally documented. Among the few available researches, Szenasy reports her teaching experience on ethical design education [10], discussing what actually the objectives, teaching methods, course contents, and assessment methods are used in design ethics education.

On the other hand, ethics education in other disciplines such as Business, Engineering, and Medicine, is relatively well-explored from the topics of content, pedagogy and curriculum to teaching tool [11-18]. Though some of them might be driven by conditional motivations for their specific circumstances, there is a common awareness within these disciplines, which include Design discipline, of a need for ethical sensitivity to the consequences of their actions in the complex, globalized marketplace and society. In response to the need, many design programs in Taiwan require ethics education.

This paper aims to identify the scope and content of ethics components in the curricula of regular 4-year undergraduate design programs in Taiwan by investigating the syllabi of ethics-related courses. The approach of studying syllabi is by its nature "input-based", that is, the contents devoted wholly or partially to ethics education would reveal, at least, a significant formalized effort toward the ethical cultivation of designers.

\section{Methods}

Existing design programs belonging to the Design Field according to the Standard Classification of Education (SCED) of the Ministry of Education (MOE) in Taiwan include four major types of design programs (TDP), namely industrial/product design (T1), graphic/visual communication/digital media design (T2), spatial/interior design (T3), and general/synthetic design (T4). These programs were collected from the Internet for further study of the syllabi. Data was obtained as follows: first, a list of institutions which provide ethics-related courses was compiled from the searching results of two web-based databases, the Curriculum Upload Systems for General and Technological \& Vocational Universities which were built by Ministry of Education and the data was regularly uploaded from all universities and colleges in Taiwan. Search range is from academic year 2008 to 2009 , and the criteria were set in two rules: 1) search all course titles containing "ethics" and program titles containing "design", 2) search all course titles containing "design ethics".

The obtained results were merged into one and then manually excluded duplicate courses, non-design programs, master programs, and programs of extension education. Of the 148 universities and colleges in Taiwan, there were 117 regular 4-year undergraduate design programs in 61 institutions during academic years 2008 and 2009. The 4-year curricula of all these targeted design programs were then further examined by searching for the word "ethics" from their websites to ensure that the obtained data was up to date. 
Table 1. Number of Design Schools and Programs in Taiwan in 2008-2009

\begin{tabular}{lllllll}
\hline & $\begin{array}{l}\text { Design } \\
\text { school }\end{array}$ & $\begin{array}{l}\text { Design } \\
\text { program }\end{array}$ & & \multicolumn{5}{l}{ Type of design program (TDP) } \\
\cline { 3 - 7 } & & & $\begin{array}{l}\text { Industrial/ } \\
\text { product design } \\
(\mathrm{T} 1)\end{array}$ & $\begin{array}{l}\text { Graphic/visual } \\
\text { communicatio } \\
\text { n/digital media } \\
\text { design } \\
\text { (T2) }\end{array}$ & $\begin{array}{l}\text { Spatial/ } \\
\text { interior } \\
\text { design }\end{array}$ & $\begin{array}{l}\text { General/ } \\
\text { synthetic } \\
\text { (T4) }\end{array}$ \\
\hline $\begin{array}{l}\text { Number - } \\
\begin{array}{l}\text { Ethics- } \\
\text { related } \\
\text { courses }\end{array}\end{array}$ & 61 & 117 & 32 & 49 & 14 & 22 \\
\hline
\end{tabular}

* There are 2 programs with 4 ethics-related courses for different years, thus the course number of $\mathrm{T} 1$ and $\mathrm{T} 2$ are 14 and 13, respectively.

A list of 33 design programs in 21 institutions containing 37 ethics related-courses was completed for syllabi collecting. Four of the 37 ethics-related courses in the list, belonging to different institutions were inaccessible or unavailable from their websites (Table 1 shows the details). In order to get broader ideas, in the remaining 33 courses, different syllabus contents for the same course in the same program because of different teachers were counted separately. Finally, a total of 38 unique syllabi were collected for content analysis and codification. Data were then processed by a qualitative method. The reason for using a qualitative approach is to get a bigger picture on what has been taught to undergraduates. The processes were as follows: first, based on the standard format of syllabus in Taiwan, the contents of syllabi were classified into four generic categories: 1) course objective, 2) course content, 3) teaching method, and 4) assessment method; however other additional statements (e.g. those pertaining to class times, locations, and instructors) were ignored. In addition, the texts in the parts of course objectives and course contents were read and open-coded, resulting in a comprehensive list of elements. The elements were then analyzed to subsume them to their respective natural and, where possible, nonoverlapping topics.

\section{Results and Discussions}

Of the 38 syllabi, five topics were identified from the parts of course objectives and contents (Table 2 shows the details). The topics are: 1) Design, 2) Profession, 3) Law, 4) Society, and 5) Life. In the parts of teaching methods and assessment methods, seven and nine methods were identified respectively. Each of the results would be discussed in detail in the following sections.

\subsection{Course Objectives and Contents}

The objectives and contents in the Design topic vary greatly. The components in this topic vary from general cross-disciplinary themes (e.g. anthropology, ecology, and 
sociology) and logical thinking, to more specific design themes such as design theories, history, and practices, and experience sharing in the design profession. The topic of Profession chiefly focuses on preparing undergraduates with good attitudes and conducts, and required knowledge and skills for the job in general (not necessarily being designers). The topic of Law discusses two major types of regulations for two different purposes. The first is introducing the laws related to the design profession, mainly Intellectual Property Right, Copyright Act, and Trademark Act. These are all very directly related to design practices and designers' interests. The second part relates to the daily life of the undergraduates. The topic of Society focuses on cultivating students with social manners and personal devotion and service to school and/or community. The Life topic is to help students understand the meaning of life and to develop the attitude to self-respect and self-realization. The proportion in terms of allocated time of teaching of each topic in a course is different. 34 out of the 38 syllabi provide weekly teaching schedules with teaching contents described. There are three kinds of combination of the topics in a course. A total of $73 \%$ of the syllabi focuses on one main topic with only 1 or 2 weeks on other topics. The main topics are Design (36\%), Life (28\%), Profession (16\%), Society (16\%), and Law $(4 \%)$. The second combination $(21 \%$ of all syllabi) contains two topics and the ratio between these two is approximately $1: 1$ or $1: 3$. In this combination, the Profession topic usually associates with Society or Law, and Design topic tends to pair with Law in the course. The third combination (6\% of all syllabi) contains three topics in a course, mostly of Design, Profession, and Law, or Profession, Law, and Society.

The influence from other disciplines, Business and Medicine, was found in the topics of Profession and Life. Since design activities often involve these two disciplines, and the development of ethics education in these disciplines is more mature than that of design, thus the influence can be positive and useful. The five topics represent different perspectives on what to teach undergraduates to orientate their role in the society: a specific profession, a job duty/title, a citizen, a social actor, and a human being. For design students and professionals, no doubt that design is a specific profession, and of course, a citizen in a community and a human being in the world; the pattern of the development of design in the 20th century is that design began as a trade activity [19], which defined design as a job duty. Not to mention the call from Papanek to turn designers into an active social actor. In fact, designer plays these five roles (or more) in different contexts. Just as Buchanan argued that design must be seen in a context of consequences that occur in many areas of human experience [20]. The diversity of the results reflects not only the complexity that designers engage in, but also the design educators. It might be even more severe in Taiwan. Code of ethics is considered an effective content in related studies [13] [14] [16], but couldn't be found in the collected syllabi since there is no written code of ethics in the related professional organizations of design in Taiwan. Hu reports that in Taiwan, most of the stakeholders had never heard of or engaged in the design codes of ethics and, most designers are not members of any related professional society [21]. These are all highly related to the development of design ethics education waiting for better understanding. 
Table 2. The Components of Course Objectives and Contents $(n=38)$

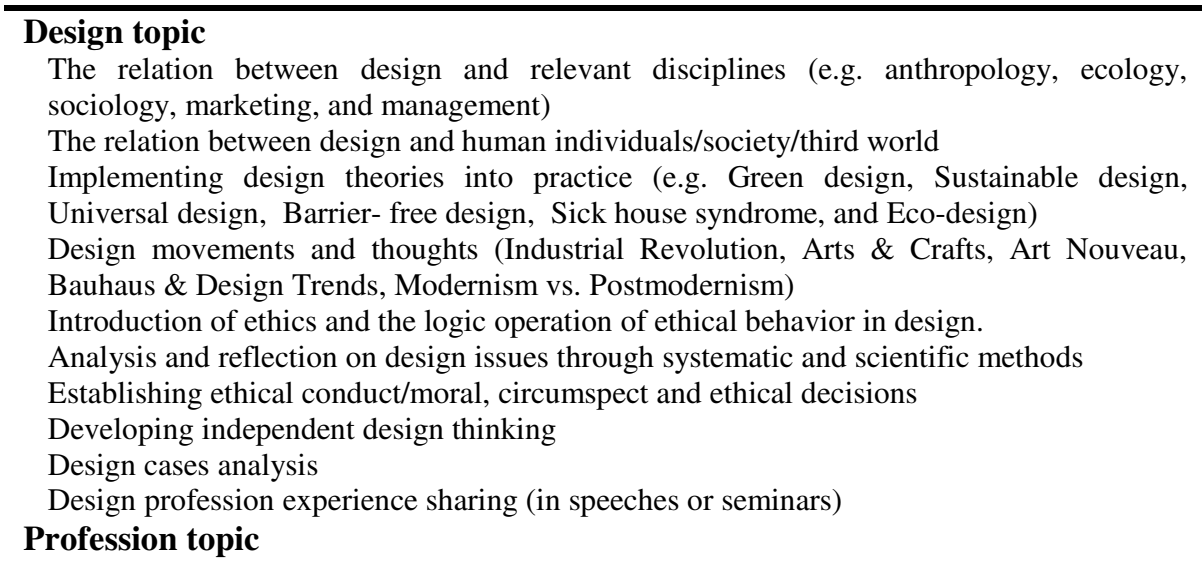

The proper work attitude, concept, and conduct towards jobs, duties, and to colleagues, subordinates, superiors

An introduction of basic concepts, principles, and practices of ethics

The differences between ethics, laws and morals.

Understanding the professional ethics from other disciplines (e.g. Basic ethics, business ethics, information ethics) and related issues, e.g., corporate social responsibility, justice

Understanding the required knowledge and skills for workplace (e.g. the management principles related to workplace, communication skills, and teamwork)

Understanding the trends of employment/career planning

The critical thinking, reflection and problem solving skills.

\section{Law topic}

Understanding design-related legal regulations (e.g. Intellectual Property Right, Patent Act, Copyright Act, Trademark Act) and their application in design practices

Understanding the legal system and legal requirements related to daily life (e.g. civil law and criminal law)

Introduction of good citizenship (e.g. understanding the meaning of democracy, respect for human rights, and compliance with legal regulations)

\section{Society topic}

Establishing a life value of helping people, and developing the spirit that benefit others as well as oneself

Developing proper etiquette and enthusiastic attitude in life

Clean the campus

Reflection on the value and meaning of life

\section{Life}

Understanding the issues of bioethics (e.g. abortion, euthanasia, suicide, death penalty, organ transplant, genetic engineering, and animal right)

Understanding the meaning of life/respect and cherish life/developing a ethical personality Enhancing the ability of social adaptation

Inspiring the concerns for other human beings, animals and the environment

The curriculum setup also differs from each other topic (Fig. 1 Shows the details). The courses focus on Design topic tend to be a professional $(73 \%)$ and required (82\%) course. The topics of Profession (75\%) and Law (71\%), though mostly required, the types of both courses are either professional or liberal. Courses focus on 


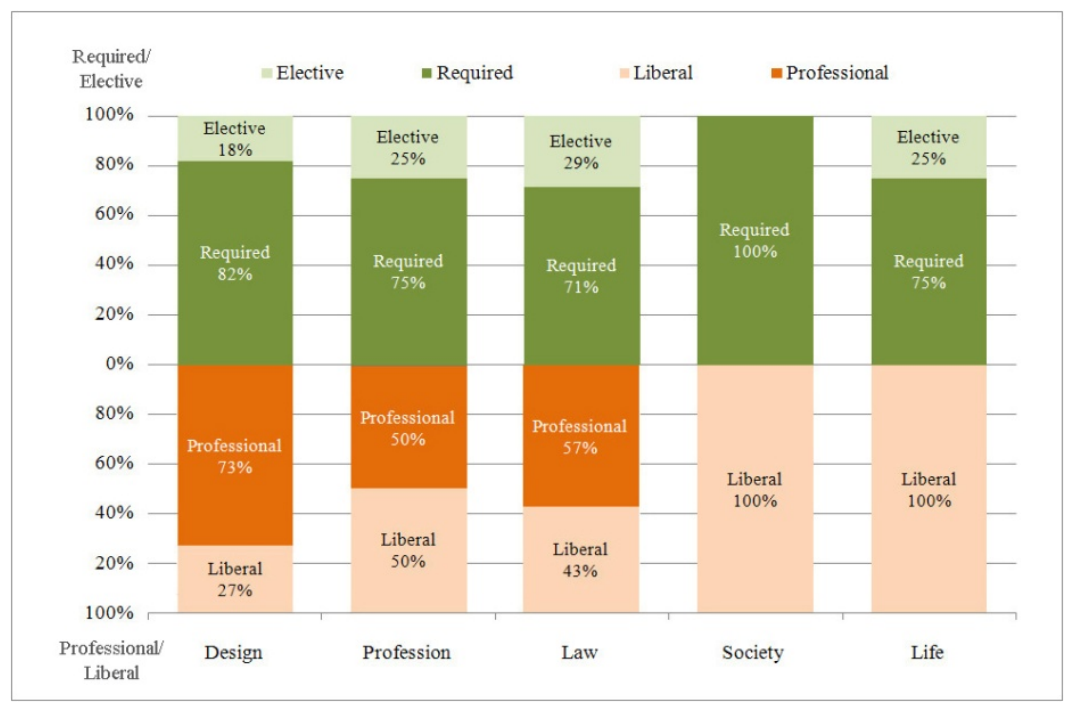

Fig. 1. Curriculum Setup -Type of Course $(n=34)$

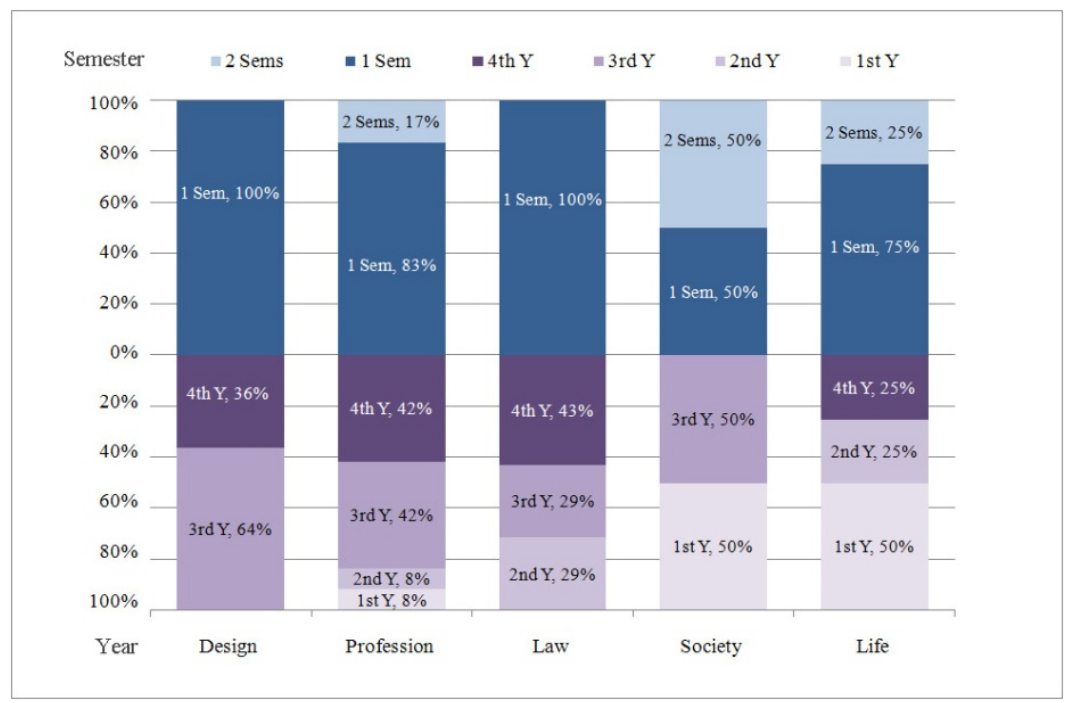

Fig. 2. Curriculum Setup - Semester and Year $(n=34)$

the Society topic are all liberal but required. The situation is broadly the same in the Life topic, only $25 \%$ is elective.

Fig. 2 shows that nearly all courses are provided in a semester (Design 100\%, Profession $83 \%$, Law $100 \%$, and Life $75 \%$ ) except the Society topic is evenly divided by two different settings (one and two semesters). The topic focuses on Design is all 
provided in the third (64\%) or fourth (36\%) year of the program and the situation of Profession is almost the same, $42 \%$ in third and fourth year respectively, except a small part in the first and second year. The rest of the three topics are provided dispersedly in the 4-year curriculum. Generally speaking, the results are coherent with a relevant study by van de Poel et al. [16]. It's reasonable and appropriate to provide ethic courses in the third or fourth year of the curriculum. By then students are more mature to confront with ethical issues, and able to oversee their field of study as a whole.

\subsection{Teaching Methods and Assessment Methods}

Seven teaching methods have been indentified from the 38 syllabi. Fig. 3 shows the frequency of each method. On average, each individual course uses 2.4 (range $=1-4$ ) methods, and most of the courses use at least 2 of them in a class (mode $=18)$. There are two methods which were used in most of the courses: lecture $(\mathrm{f}=35)$ and discussion \& report $(\mathrm{f}=30)$.

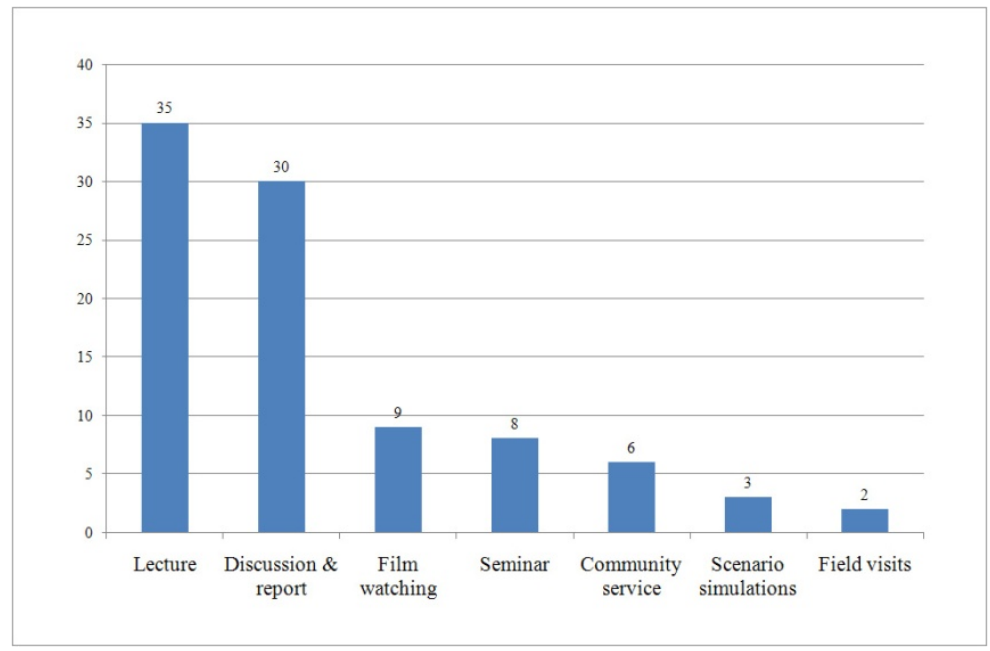

Fig. 3. Types and Frequencies of Teaching Methods $(n=38)$

The use of teaching method during the semester was described in the 34 syllabi in their weekly teaching schedule (Fig. 4 Shows the details). Not surprisingly, lecture (63.5\%) was used most of the time in the class, the second is discussion \& report $(22.7 \%)$, and the rests $(13.7 \%)$ are used as supplements in teaching, e.g. inviting practitioners to share experiences on the ethical topics (seminar). The results tally with relevant studies [13] [17] that discussion is a frequently used method, and a good way to guide and spur students to an ethical thinking [10]. 


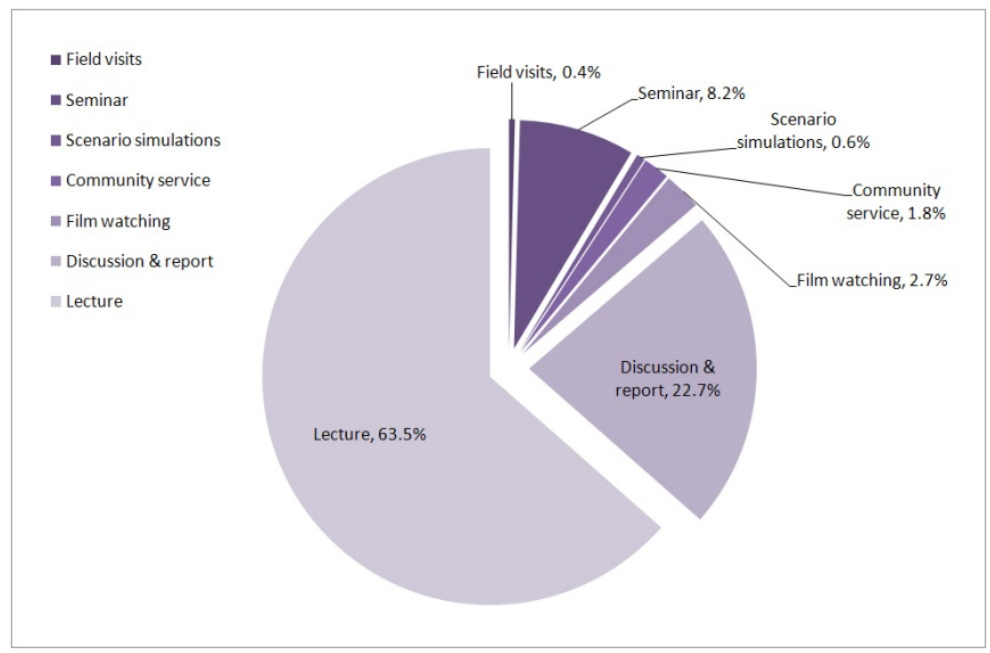

Fig. 4. The Use of Teaching Methods ( $n=34)$

Nine assessment methods were indentified from the 38 syllabi. Fig. 5 shows the frequency of each method. On average, each individual courses uses 2.71 (range $=0$ 6) methods, and most of the courses use 4 of the assessment methods in a class (mode $=10)$. The top 4 methods were attendance $(\mathrm{f}=21)$, class participation $(\mathrm{f}=15)$, examination $(\mathrm{f}=15)$, and written report $(\mathrm{f}=15)$. The results also conform to a related study by Herket [13]. In addition, the fact that attendance and class participation are commonly used in ethics course imply that the teaching effects on ethics is hard to evaluate thus the strategy of teaching ethics is encouraging more participation thereby affecting the concepts and behaviors.

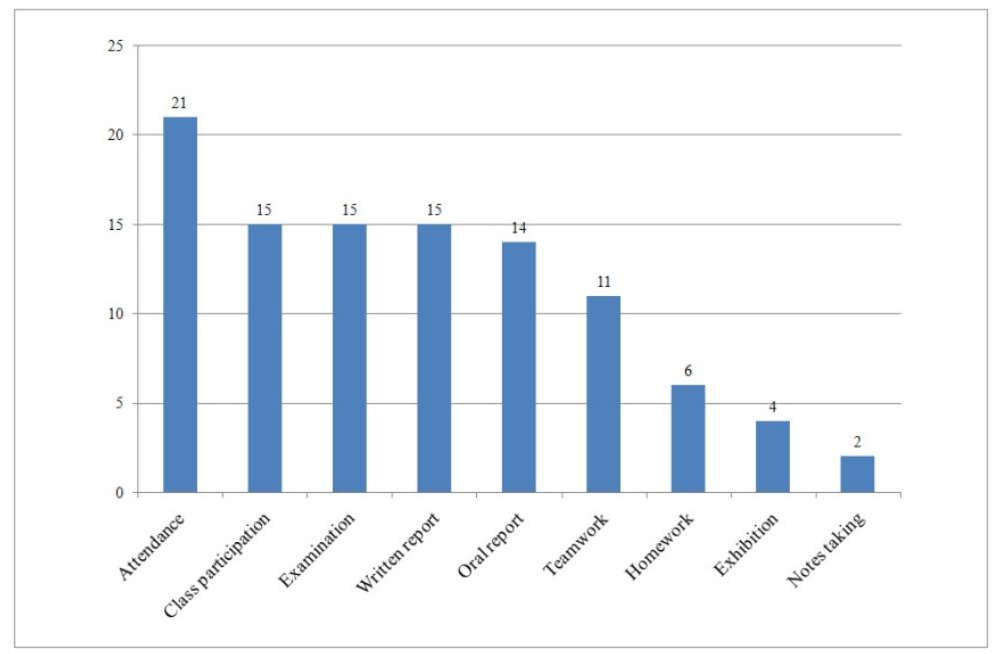

Fig. 5. Types and Frequencies of Assessment Methods $(n=38)$ 


\section{Conclusions and Further Research}

This is a preliminary study of design ethics education. The results are not seeking for answers, instead, helping to ask (or find) the right questions. It might tell nothing about the quality of such instruction or how well undergraduate design students understand ethical responsibility as a result. However, it achieved the aim that it reveals the circumstance of what and how we treat ethics as a topic in design education in Taiwan. Thereby, we conclude with some suggestions on the agenda of research on design ethics education.

First, the findings show that ethics in design education is far from homogeneous among design schools in Taiwan. Compared with the ethics education in other disciplines such as engineering or medicine, the opinions of how to educate future designers to orientate their role in the society vary considerably. There is still no consensus on the scope and content for ethics in design. Nevertheless, there are welldeveloped ethics educations in other disciplines, e.g. Business, Engineering, and Medicine, providing important examples and point of reference for us to make our own choices. The advantage is that design is involved with all these disciplines. Based on the results and the references we may draw up an ideal ethics curriculum for design program and seek for opinions and consensus in the design field.

Design does not yet have an accrediting organization that stipulates strong moral norms in ethics education. In Taiwan the notion of design as a profession is less dominant than in other countries such as Japan, US, and UK. Most of the stakeholders have never heard of or engaged in the design codes of ethics and, most designers generally are not members of any related professional society. The call for paying serious attention to design ethics education rose in society once a while only when significant events occurred but soon been forgotten. These phenomena are all critical, and highly related to the development of design ethic education which should be investigated follow up.

Ethics education is a part of character formation. As Buchanan mentions that talking about character and character formation faces many challenges, still he urges that we must move into these turbulent waters [20]. Design is playing an important part in our life from many aspects individually and globally. We consider this a major challenge with respect both to teaching and to research, but inevitably need to be done responsibly.

Acknowledgment. This paper was partly supported by the National Science Council of the Republic of China under Project No.: NSC 98-2410-H-224 -026.

\section{References}

1. Yang, M.Y., You, M., Han, C.Y.: A study of industrial design students' employment preparation and choices in Taiwan. Art, Design \& Communication in Higher Education 9(1), 21-40 (2010)

2. Yang, M.Y., You, M.: A survey of career guidance needs of industrial design students in Taiwanese Universities. Asia Pacific Education Review 11(4), 597-608 (2010)

3. Papanek, V.: Design for the Real World: Human ecology and social change, 2nd edn. Thames \& Hudson, London (1985) 
4. Whiteley, N.: Design for Society. Reaktion, London (1993)

5. Nieusma, D.: Alternative Design Scholarship: Working Toward Appropriate Design. Design Issues 20(3), 13-24 (2004)

6. Oosterlaken, I.: Design for Development: A Capability Approach. Design Issues 25(4), 91-102 (2009)

7. Thomas, A.: Design, Poverty, and Sustainable Development. Design Issues 22(4), 54-65 (2006)

8. Margolin, V., Margolin, S.: A "Social Model" of Design: Issues of Practice and Research. Design Issues 18(4), 24-30 (2002)

9. Morelli, N.: Social Innovation and New Industrial Contexts: Can Designers "Industrialize" Socially Responsible Solutions? Design Issues 23(4), 3-21 (2007)

10. Szenasy, S.S.: Ethical Design Education: Confession of a Sixties Idealist. In: Heller, S., Vienne, V. (eds.) Citizen Designer: Perspectives on Design Responsibility, pp. 20-24. Allworth Press, N.Y. (2003)

11. Bero, B., Kuhlman, A.: Teaching Ethics to Engineers: Ethical Decision Making Parallels the Engineering Design Process. Science and engineering ethics. Published online (June 04, 2010)

12. Chung, C.A., Alfred, M.: Design, Development, and Evaluation of an Interactive Simulator for Engineering Ethics Education (SEEE). Science and Engineering Ethics 15(2), 189-199 (2009)

13. Herkert, J.R.: Engineering Ethics Education in the USA: Content, Pedagogy and Curriculum. European Journal of Engineering Education 25(4), 303-313 (2000)

14. Rabins, M.J.: Teaching engineering ethics to undergraduates: Why? What? How? Science and Engineering Ethics 4(2), 291-302 (1998)

15. Stephan, K.D.: A survey of ethics-related instruction in U.S. engineering programs. Journal of Engineering Education 88(4), 459-464 (1999)

16. van de Poel, I.R., Zandvoort, H., Brumsen, M.: Ethics and engineering courses at Delft University of Technology: Contents, educational setup and experiences. Science and Engineering Ethics 7(2), 267-282 (2001)

17. DuBois, J.M., Burkemper, J.: Ethics education in U.S. medical schools: a study of syllabi. Academic Medicine 77(5), 432-437 (2002)

18. Robin, D.: Toward an Applied Meaning for Ethics in Business. Journal of Business Ethics 89(1), 139-150 (2009)

19. Buchanan, R.: Education and Professional Practice in Design. Design Issues 14(2), 63-66 (2001)

20. Buchanan, R.: The Problem of Character in Design Education: Liberal Arts and Professional Specialization. International Journal of Technology and Design Education 11, 13-26 (2001)

21. Hu, Y.C.: On professional ethics and the construction of a code of ethics for industrial designers in Taiwan. National Yunlin University of Science and Technology, Yunlin, Taiwan. Unpublished master thesis (2010) (in Chinese) 